\title{
p-NITROPHENYL AND p-NITROBENZOYL DERIVATIVES OF O,O' - ALKYLENE DITHIOPHOSPHATE
}

\author{
LEENA CHORDIA AND ALOK CHATURVEDI*
}

Department of Chemistry, Government College, Ajmer - 305001, India

(Received: May 28, 2007 - Accepted: March 4, 2008)

\begin{abstract}

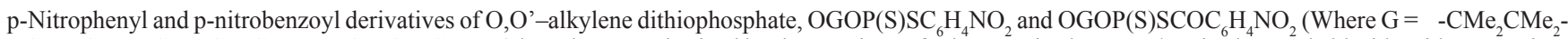
, - $\mathrm{CH}_{2} \mathrm{CMe}_{2} \mathrm{CH}_{2}-,-\mathrm{CMe}_{2} \mathrm{CH}_{2} \mathrm{CHMe}-,-\mathrm{CH}_{2} \mathrm{CH}_{2} \mathrm{CHMe}-$ ) have been synthesized by the reactions of p-bromo nitrobenzene / p-nitrobenzoyl chloride with ammonium salt of alkylene dithiophosphoric acids. These derivatives are yellow and red coloured solids, respectively and are soluble in common organic solvents. These are characterized by elemental analysis, IR and NMR $\left({ }^{1} \mathrm{H}\right.$ and $\left.{ }^{31} \mathrm{P}\right)$ spectral studies. In contrast to the bi-dentate chelating behaviour of the ligand in the metal and organometal derivatives of alkylene dithiophosphates, the behaviour of dithiophosphato moiety in these derivatives is found to be mono-dentate in nature.
\end{abstract}

Keywords :- p-Bromo nitrobenzene, p-nitrobenzoyl chloride, ammonium salt of alkylene dithiophosphoric acids.

\section{INTRODUCTION}

Alkylene dithiophosphoric acids are known as cyclic analogous of dialkyl dithiophosphoric acid (open chain) ${ }^{1}$. Large number of organic derivatives of dialkyl dithiophosphate have been described in the early literature ${ }^{2-4}$ but the corresponding organic derivatives of alkylene dithiophosphate are still less known ${ }^{5-8}$.

The chemistry of metal alkylene dithiophosphates has been extensively reported in the literature ${ }^{9-12}$. Alkylene dithiophosphate and their metal derivatives are used as agro chemical ${ }^{13}$, oil additive ${ }^{14}$, antioxidant ${ }^{15}$ and as floating agents ${ }^{16}$.

The present paper deals with the corresponding reaction of p-bromo nitrobenzene and p-nitrobenzoyl chloride with ammonium salt of alkylene dithiophosphates.

\section{EXPERIMENTAL}

Ammonium salts of $\mathrm{O}, \mathrm{O}$ '-alkylene dithiophosphoric acids, p-bromo nitrobenzene and p-nitrobenzoyl chloride have been synthesized by the methods reported in the literature ${ }^{14}$. All the solvents used during present investigation, were of reagent grade and even made anhydrous by standard methods. Sulphur was estimated gravimetrically as barium sulphate (Messenger's method) ${ }^{17}$. Molecular weights were determined by Knauer vapour pressure osmometer in chloroform. FTIR spectra were recorded on Shimadzu 8201 PC spectrophotometer in the range of $4000-400 \mathrm{~cm}^{-1}$ using CsI cells. ${ }^{1} \mathrm{H}$ NMR spectra were recorded in $\mathrm{CDCl}_{3}$ and ${ }^{31} \mathrm{P}$ NMR spectra were recorded in benzene on Bruker DRX 300 spectrophotometer using TMS (for ${ }^{1} \mathrm{H}$ ) and $\mathrm{H}_{3} \mathrm{PO}_{4}\left(\right.$ for ${ }^{31} \mathrm{P}$ ) as external references.

Reaction of p-nitrobenzoyl chloride with ammonium tetramethyl ethylene dithiophosphate

Ammonium tetramethyl ethylene dithiophosphate $(1.12 \mathrm{~g} ; 4.89 \mathrm{mmole})$ was refluxed with p-nitrobenzoyl chloride $(0.92 \mathrm{~g} ; 4.96 \mathrm{mmole})$ in anhydrous benzene for $6 \mathrm{hrs}$. Ammonium chloride was removed by filteration. Yellow coloured product was separated out by removing the solvent from the filterate. The product was washed 3-4 times with n-hexane and recrystallized (Calcd. for- $\mathrm{OCMe}_{2} \mathrm{CMe}_{2} \mathrm{OP}(\mathrm{S}) \mathrm{SC}(\mathrm{O}) \mathrm{PhNO}_{2} \mathrm{H}=4.43 \%, \quad \mathrm{C}=43.21 \%, \mathrm{~S}=17.73 \%$ ) Found $-\mathrm{H}=4.36 \%, \mathrm{C}=42.98 \%, \mathrm{~S}=17.60 \%$ ).

\section{RESULTS AND DISCUSSION}

Synthesis of p-nitrophenyl derivatives of alkylene dithiophosphate have been successfully carried out by the reactions of p-bromo nitrobenzene with ammonium salts of alkylene dithiophosphoric acid in anhydrous benzene for $10 \mathrm{hrs}$. Ammonium bromide is precipitate out as side product and is being removed by filtration. Then the product is obtained by striping off the solvent from the filtrate.

p-nitro benzoyl derivatives of alkylene dithiophosphate have been prepared by similar method.

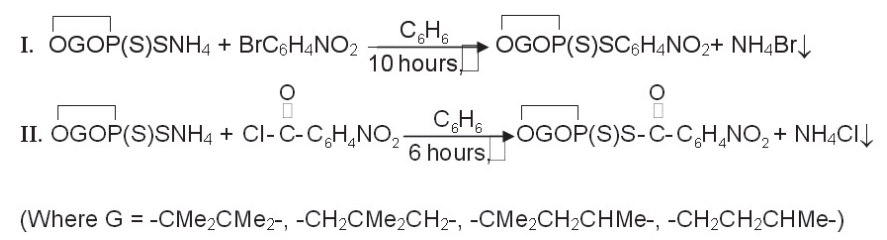

During the reaction period, it has been observed that the colour of reaction mixture (I) changes from colourless to yellow and as the reaction progressed, it becomes dirty yellow while colour of reaction mixture (II) changes from colourless to reddish yellow and as the reaction progressed, it becomes red. Reaction (II) seem to be fast in comparison to reaction (I). It appears that due to the presence of deactivating carbonyl group, nucleophilic displacement of chloride ion by dithiophosphato moiety becomes easy. So these reactions require short duration in comparision to reaction of p-bromo nitrobenzene with ammonium salt of alkylene dithiophosphates, for completion. The products, thus obtained are yellow and red coloured solids, soluble in common organic solvents but are insoluble in $n$-hexane and are purified by washing 3-4 times with $\mathrm{n}$-hexane and then re-crystallized.

\section{SPECTRAL ANALYSIS}

\section{IR Spectra}

IR spectra of these derivatives are summarized in Table-2 and show the following characteristic changes:

(1) An absorption band at $3080-3060 \mathrm{~cm}^{-1}$ in all the compounds may be ascribed to aromatic $\mathrm{C}-\mathrm{H}$ stretching vibrations.

(2) Nitro group in these derivatives show strong absorption band at 1550$1520 \mathrm{~cm}^{-1}$ which show slight shift towards lower wave number (15 $\mathrm{cm}^{-1}$ ) in comparison to p-bromo nitrobenzene. It may be due to lesser nucleophilicity of dithiophosphato moiety in comparison to bromine atom present in p-bromo nitrobenzene.

(3) The absorption band present in the region $1145-1130 \mathrm{~cm}^{-1}$ and $885-870$ $\mathrm{cm}^{-1}$ may be assigned to (P)-O-C and P-O-(C) stretching vibrations, respectively.

(4) A strong absorption band due to dioxaphospholone and dioxaphosphorinane ring vibrations is present in the region $955-800 \mathrm{~cm}^{-1}$.

(5) A sharp band assigned to $v \mathrm{P}=\mathrm{S}$ absorptions in the region $860-810 \mathrm{~cm}^{-1}$ show shifting towards higher frequency with respect to its position in the free ligand. This shifting is due to presence of deactivating nitro group in the aromatic ring.

(6) A new band has been observed in the region 710-625 $\mathrm{cm}^{-1}$ due to the carbon-sulphur bond. Appearance of this band supports the formation of $\mathrm{P}$-(S)S- -0 - $\mathrm{NO}_{2}$ and $\mathrm{P}(\mathrm{S}) \mathrm{S}-\stackrel{\mathrm{D}}{\mathrm{C}}-\mathrm{O}-\mathrm{O}-\mathrm{NO}_{2}$ linkage in these derivatives.

(7) The absorption bands of medium intensity in the region $565-540 \mathrm{~cm}^{-1}$ have been attributed to $\mathrm{vP}-\mathrm{S}$ asymmetric and symmetric vibrations. 
Syntheses of similar derivatives are summarized in Table- 1 .

Table.1. Synthetic and analytical data of p-nitrophenyl and p-nitrobenzoyl derivatives of O,O'-alkylene dithiophosphates.

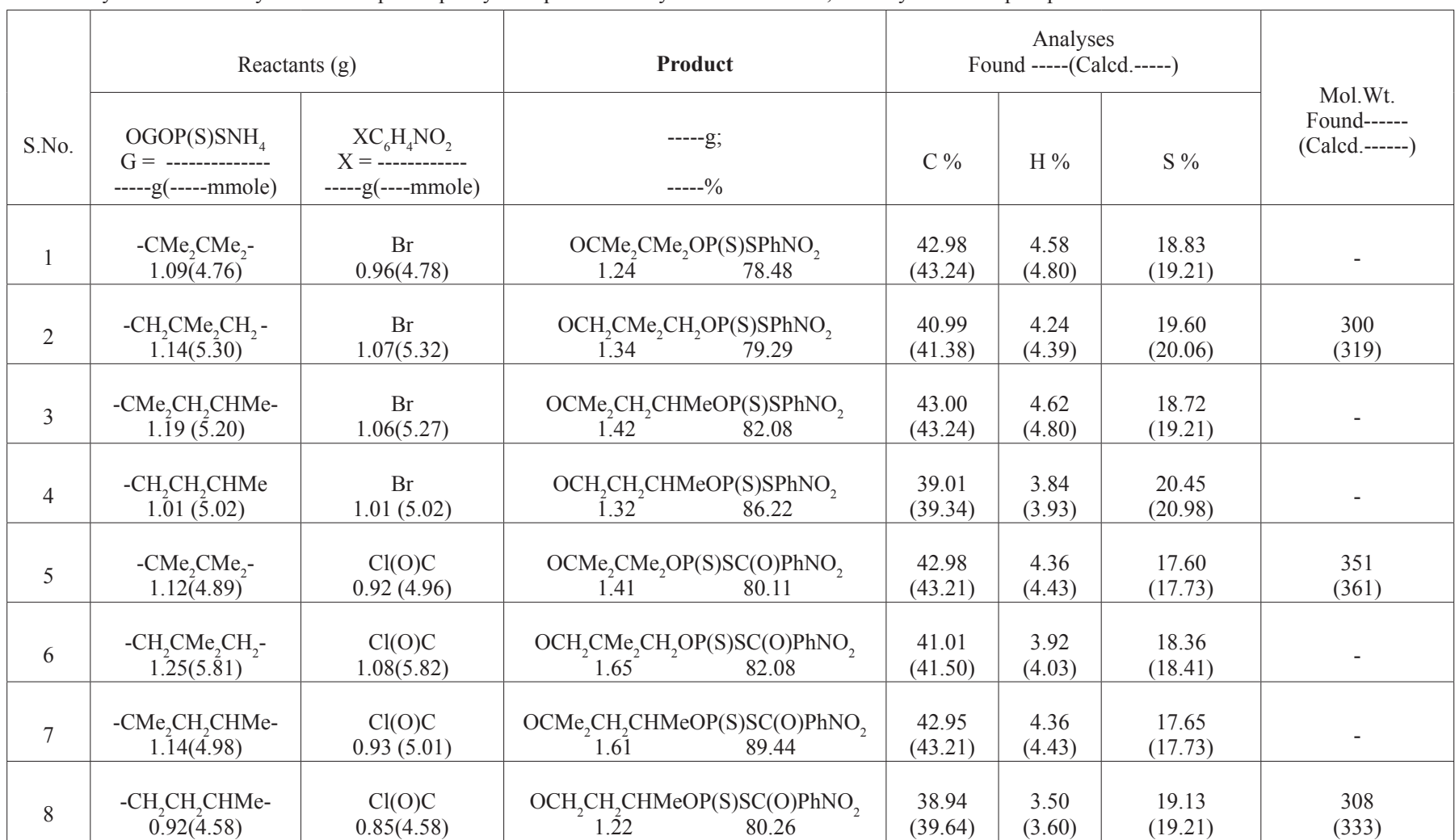

Table 2. IR spectral data of p-nitrophenyl and p-nitrobenzoyl derivatives of O,O' - alkylene dithiophosphates

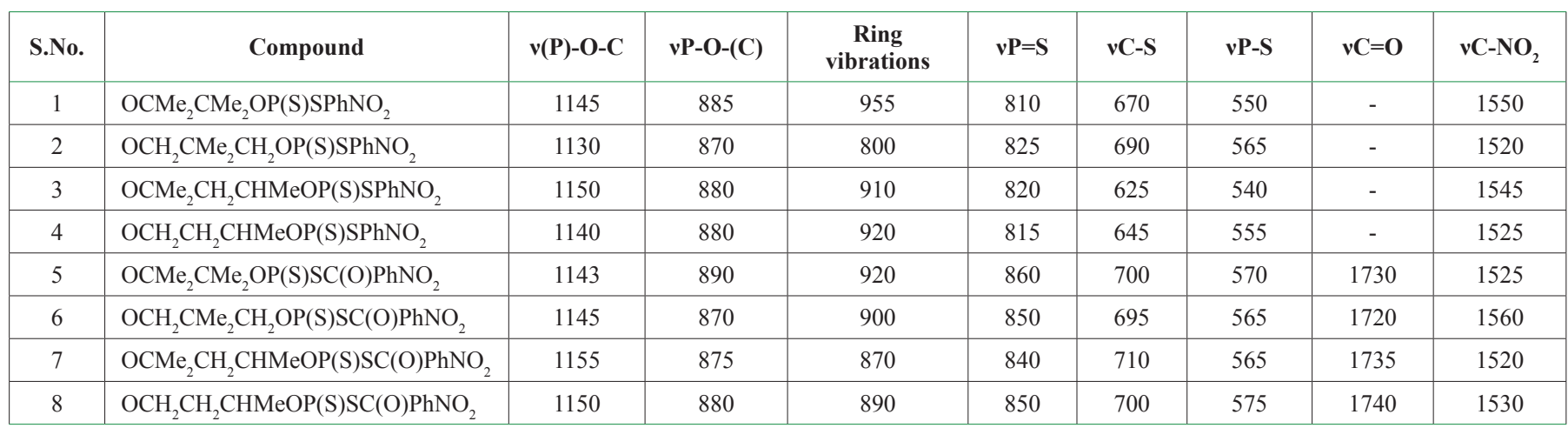

Table 3. ${ }^{1} \mathrm{H}$ and ${ }^{31} \mathrm{P}$ NMR spectral data of p-nitropenyl and p-nitrobenzoyl derivatives of $\mathrm{O}, \mathrm{O}{ }^{\prime}-$ alkylene dithiophosphates

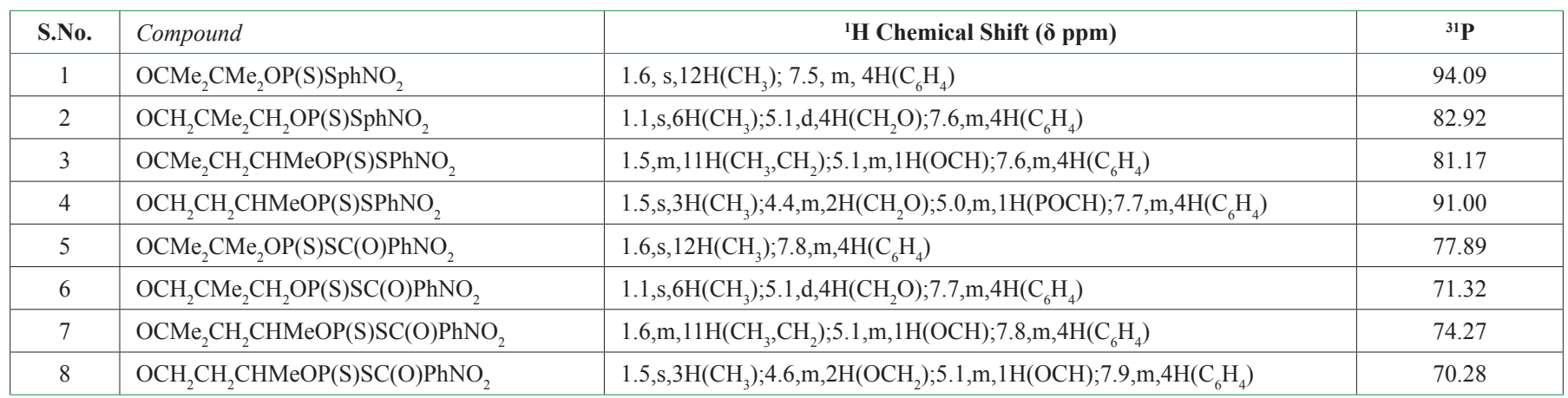




\section{${ }^{1} \mathrm{H}$ NMR spectra}

${ }^{1} \mathrm{H}$ NMR spectral data of these derivatives are tabulated in Table-3 and show characteristic resonance signal due to glycoxy and aromatic protons. A multiplet for $-\mathrm{OCH}_{2}$ and $-\mathrm{OCH}$ protons have been observed at 5.1-4.4 and 5.1-5.0 ppm, respectively.

A multiplet has been observed for the $\mathrm{P}-\mathrm{O}-\mathrm{CH}_{2}$ and $\mathrm{P}-\mathrm{O}-\mathrm{CH}$ protons which is due to 3-bond coupling of the protons with phosphorus atom. A multiplet at 7.7-7.5 ppm has been observed which is ascribed to aromatic protons.

\section{${ }^{31}$ P NMR Spectra}

${ }^{31} \mathrm{P}$ NMR spectra of these derivatives are given in Table- 3 and show only one resonance signal in the region 94.09-70.28 ppm. On comparison with parent dithiophosphoric acid, it has been observed that derivatives of the type $\underset{\mathrm{OGOP}}{\mathrm{S}} \mathrm{SSC}_{6} \mathrm{H}_{4} \mathrm{NO}_{2}$ (I) and $\mathrm{OGOP}(\mathrm{S}) \mathrm{S}-\stackrel{\mathrm{D}}{\mathrm{C}}-\mathrm{C}_{6} \mathrm{H}_{4} \mathrm{NO}_{2}$ (II) shows down-field (5$12 \mathrm{ppm}$ ) and up-field (4-10 ppm) shifting, respectively. The up-field shifting of these derivatives appears due to the presence of deactivating carbonyl group.

\section{CONCLUSION}

On the basis of elemental analysis, molecular weight measurements and spectral analysis (IR, ${ }^{1} \mathrm{H}$ and ${ }^{31} \mathrm{P}$ NMR), monodentate nature of alkylene dithiophosphate moiety has been established. Following tentative structure may be proposed for the newly synthesized complexes.

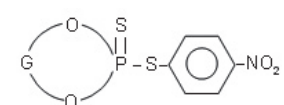

(1) p-nitrophenyl - 0,0'-alkylene dithiophosphate

\section{ACKNOWLEDGEMENT}

One of the authors (Leena Chordia) is grateful to C.S.I.R., New Delhi for Financial Assistance as J.R.F. and S.A.I.F. (C.D.R.I.), Lucknow for spectral analysis.

\section{REFERENCES}

1. B.P.S. Chauhan, G.Srivastava and R.C. Mehrotra, Coord. Chem. Revs. 55, 207 (1984)

2. L. Almasi, A. Hantz, V.T. Baisu, Chem. Ber., 104, 3982 (1971)

3. L. Almasi, U.H. Hantz, Chem. Ber., 103, 718 (1970)

4. M.G. Zimin, M.M. Afanasav, U.A.N. Pudovik Zh. Obsh. Khim., 50, 746 (1980)

5. R. Purwar and P.N. Nagar, Phosphorus, Sulfur and Silicon and the related elements, 86, 211-215 (1994)

6. R. Purwar, M.K. Sharma, R.K. Sharma and P.N. Nagar, Phosphorus, Sulfur and Silicon and the related elements, 174, 15-23 (2001)

7. N. Harkut and P.N. Nagar, Phosphorus, Sulfur and Silicon and the related elements, 180 (11), 2517-2524 (2005)

8. C.S. Sharma and P.N. Nagar, Phosphorus, Sulfur and Silicon and the related elements, 181(2), 453-460 (2006)

9. A. Chaturvedi, P.N. Nagar and G. Srivastava, Main Group Met. Chem., 16 (1), 45-52 (1993)

10. O.P. Singh, A. Chaturvedi, R.K. Mehrotra and G. Srivastava, Phosphorus, Sulfur and Silicon, 82, 31-37 (1993)

11. A. Chaturvedi, P.N. Nagar and G. Srivastava, Phosphorus, Sulfur and Silicon, 90, 229-233 (1994)

12. A. Chaturvedi, P.N. Nagar and A.K. Rai, Synth. React. Inorg. Met-Org. Chem., 26 (6), 1025-1033 (1996)

13. M.Wm., Lanham. Brit. 819, 424 (1958); C.A., 54, 13149 (1960)

14. L.M. Lichard and W.C. Harry, U.S., 3,089,850 (1957); C.A., 59, 11250 (1983)

15. H.B. Joffery, U.S., 3,159,664 (1960); C.A. 62, 7639 (1965)

16. H.B. Joffery, B.L. Samval and A.M. Louis, U.S.,3,92,162 (1965); C.A. 63, 14703 (1967).

17. A.I. Vogel "A Test Book of Quantitative Inorg Analysis" ELBS IV Edition, London (1973). 